\title{
Re-mineralization potential, shear bond strength and hydration characteristics of experimentally prepared tri-calcium aluminate phase-modified glass ionomer cement on sound and caries-affected dentin (An in vitro/in vivo study)
}

\author{
M. M. Radwan' ${ }^{1}$ H. K. Abd EL-Hamid² and Shaymaa M. Nagi ${ }^{3^{*}}$ (1)
}

\begin{abstract}
Background: This study aimed to in vivo and in vitro evaluate the remineralization potential and shear bond strength (SBS) of experimentally prepared tri-calcium aluminate $\left(C_{3} A\right)$-modified glass ionomer cements on sound and artificial caries-affected dentin (CAD). A pure tricalcium aluminate $\left(C_{3} A\right)$ phase prepared via solid state reaction at elevated temperature from chemically pure calcium carbonate and alumina, to formulate ceramic composite of composition: $75 \% \mathrm{C}_{3} \mathrm{~A}, 15 \% \mathrm{CaSO}_{4} \cdot 2 \mathrm{H}_{2} \mathrm{O}$ and $10 \% \mathrm{Bi}_{2} \mathrm{O}_{3}$. The influence of artificial saliva solution on the hydration characteristics and microstructure of the synthesized composite was investigated by X-ray diffraction (XRD) analysis, FTIR spectral analysis, pH determination and scanning electron microscope (SEM) in comparison with distilled water curing medium. Modified cements of $C_{3} A$ glass ionomers $\left(C_{3} A-C G I C\right)$ were prepared by addition of the experimentally prepared $\mathrm{C}_{3} \mathrm{~A}$ to the powder component of the conventical glass ionomer cement (CGIC). Five and $10 \mathrm{wt} \%$ of $\mathrm{C}_{3} \mathrm{~A}$ CGICs powder were prepared and compared to CGIC. Cements were applied in prepared class V cavities in rabbits' teeth either to sound or artificial CAD. All rabbits were killed after 15 days, and then, Ca and P wt\% were evaluated at the cement-dentin interface using Energy-Dispersive X-ray Analysis. Specimens for SBS evaluation were prepared for the tested cements bonded either to sound or artificial CAD, then tested using universal testing machine.

Results: The XRD results indicate that there is an acceleration effect on the hydration reactions and decrease in the rate of conversion process of $C_{3} A$ phase composite due to the presence of free ions in saliva solution which was emphasized by the results of the IR spectral bands of the hydrated paste samples. The SEM micrographs showed a more-dense microstructure with large accumulations of aluminate hydrate crystals of samples cured under saliva solution. Results of the prepared $\mathrm{C}_{3} \mathrm{~A}-\mathrm{CGIC}$ showed that $10 \mathrm{wt} \% \mathrm{C}_{3} \mathrm{~A}-\mathrm{GIC}$ group had the highest statistically significant mean $\mathrm{Ca}, \mathrm{P}$ wt\% and SBS values on CAD compared to $5 \mathrm{wt} \% \mathrm{C}_{3} \mathrm{~A}-\mathrm{GIC}$ and $\mathrm{CGIC}$.
\end{abstract}

\footnotetext{
*Correspondence: smnagi@gmail.com

${ }^{3}$ Restorative and Dental Materials Department, National Research Centre

(NRC), 33 El Bohouth st. (former El Tahrir st.), Dokki 12622, Cairo, Egypt

Full list of author information is available at the end of the article
} 
Conclusions: $10 \mathrm{wt} \% \mathrm{C}_{3} \mathrm{~A}-\mathrm{GIC}$ has a remineralizing effect on artificial CAD under in vivo conditions, plus its improved bonding to dentin compared to CGIC. Thus, it might be promising restorative/base with advanced remineralization potential and adequate bond strength to both sound dentin and CAD.

Keywords: Tricalcium aluminate, Hydrogarnet, Glass ionomer cement, Caries-affected dentin, Remineralization, Shear bond strength, Cement dentin interface

\section{Background}

Since the introduction of glass ionomer cements in 1972, it has been widely used in clinical dentistry. Glass ionomers have many favorable characteristics including; chemical adhesion to the tooth structure and sustained release of fluoride over a prolonged time. On the other hand, glass ionomer cements have some restrictions in their clinical applications due to their low early mechanical properties and moisture sensitivity during the initial stages of the setting reaction (Hasenwinkel et al. 2013). Thus, many modifications were introduced to the glass ionomers original formulations aiming to improve its properties. These modifications include alternative filler particles (e.g., different metal oxides) and/or matrix setting reaction (e.g., resinous formulation) (Rahaman et al. 2011; Ezz et al. 2018).

A new category of dental cements has been emerged within the last two decades. Similar to the calcium silicate cements (CSCs), the calcium aluminate cements (CAC) are also originated from the class of cements called "hydraulic" or natural cements (Jefferies 2014). Tri-calcium aluminate phase $\left(\mathrm{C}_{3} \mathrm{~A}\right)$ is one of the major phases of mineral trioxide (MTA) material. Calcium aluminate $\left(\mathrm{C}_{3} \mathrm{~A}\right)$ phase has been used as biomedical material in many applications as it enhances the hydration chemical reactions with a continuous dissolution/precipitation process which maintain sufficient seal insoluble in tissue fluid and non-resorbable. The calcium aluminate cements have high levels of calcium, display a $\mathrm{pH}$ in the alkaline range, and they are bioactive as they are able to form surface apatite in the presence of a simulated body fluid (SBF) (Camilleri et al. 2005; Dammaschke et al. 2005; Sarkar et al. 2005).

Due to the favorable properties of calcium aluminate, modifying the conventional glass ionomer cements (CGIC) with it could enhance the glass ionomer cement composition (Jefferies 2014). Thus, the present work aimed to study the influence of curing media, namely distilled water and saliva solution on the hydration reactions of composite material based on tri-calcium aluminate phase $\left(\mathrm{C}_{3} \mathrm{~A}\right)$ to be used as biomaterial for dental applications. Investigation of hydration reaction characteristics and morphology of the hardened pastes were carried out. Furthermore, in vivo evaluation of the remineralization potential of the experimentally prepared tri-calcium aluminate added to glass ionomer cements with different concentrations in class $\mathrm{V}$ prepared cavities applied on sound and artificial caries-affected dentin. Moreover, the shear bond strength of tri-calcium aluminate-modified glass ionomer cements was also tested on both sound and caries-affected dentin.

\section{Methods}

\section{Preparation of calcium aluminate phase}

A dry mixture of $3: 1 \mathrm{CaCO}_{3}$ and $\mathrm{Al}_{2} \mathrm{O}_{3}\left[\mathrm{CaCO}_{3}(\approx 99.8 \%)\right.$ and $\left.\mathrm{Al}_{2} \mathrm{O}_{3}(\approx 99.6 \%)\right]$ was used to synthesize the $\mathrm{C}_{3} \mathrm{~A}$ phase. All chemicals used in this investigation were supplied by BDH Chemicals Ltd, Poole, England. The mixture was homogenized using an electric roller for $24 \mathrm{~h}$ and then pressed into 2-inch cubes and calcined at $1000{ }^{\circ} \mathrm{C}$ for $2 \mathrm{~h}$ in Vecstar electric furnace. The produced material was milled and then remolded in 2-inch cubes and fired at $1350{ }^{\circ} \mathrm{C}$ for $3 \mathrm{~h}$. This solid-state reaction was carried out in accordance with the phase diagram of calcium aluminate phases at a temperature needed for tricalcium aluminate phase formation $\left(\mathrm{C}_{3} \mathrm{~A}\right)$ (Taylor 1997). Firing process was repeated until nearly complete formation of the phase. The final product was tested for their free lime and insoluble residue contents. The resulting material was finely ground for $15 \mathrm{~h}$ in an electric milling machine (Retsch GmbH PM100, Germany) to pass completely through a $53 \mu \mathrm{m}$ (270 mesh) standard sieve and packed in a plastic container. The final phase powder was characterized by its X-ray diffraction (XRD) pattern (Fig. 1) and Transmission Electron Microscopy (TEM) ((JEM-1230) at $100 \mathrm{kV}$ ) for the particle size (Fig. 2).

The synthesized $\mathrm{C}_{3} \mathrm{~A}$ phase was used to formulate the composite material of the following weight percentages:-

- $75 \mathrm{wt} \% \mathrm{C}_{3} \mathrm{~A}$ phase.

- $15 \mathrm{wt} \%$ chemically pure $\mathrm{CaSO}_{4} \cdot 2 \mathrm{H}_{2} \mathrm{O}$ (gypsum).

- $10 \mathrm{wt} \%$ chemically pure Bismuth Oxide $\left(\mathrm{Bi}_{2} \mathrm{O}_{3}\right)$.

The desired amount of the composite material was dry mixed, homogenized and finely ground for $3 \mathrm{~h}$ using a milling machine (Retsch GmbH PM100, Germany) to pass the above mentioned 270 mesh standard sieve. Bismuth Oxide $\left(\mathrm{Bi}_{2} \mathrm{O}_{3}\right)$ was added to the mix composition as a radio pacifier material. 


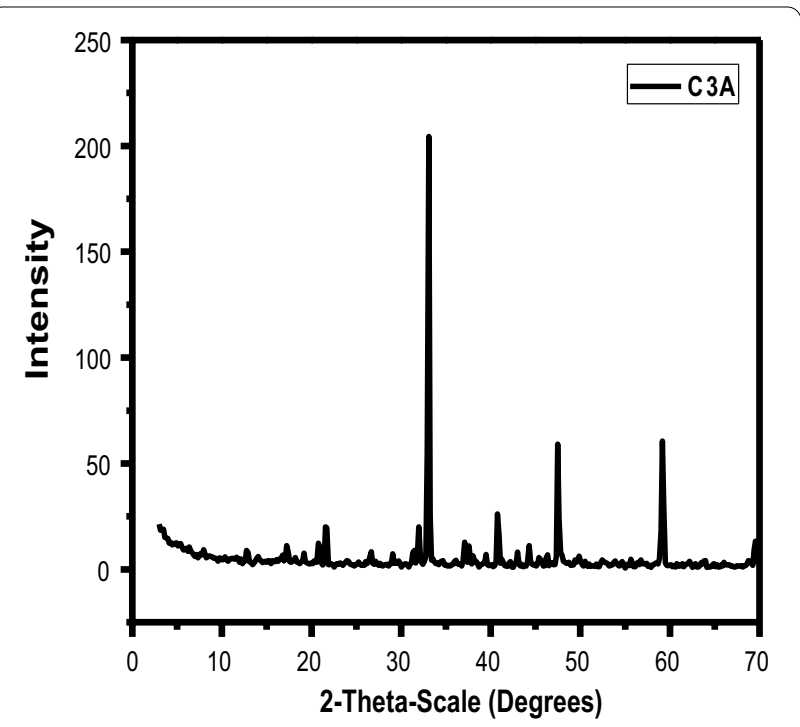

Fig. 1 X-ray diffraction pattern of pure $C_{3} A$ phase

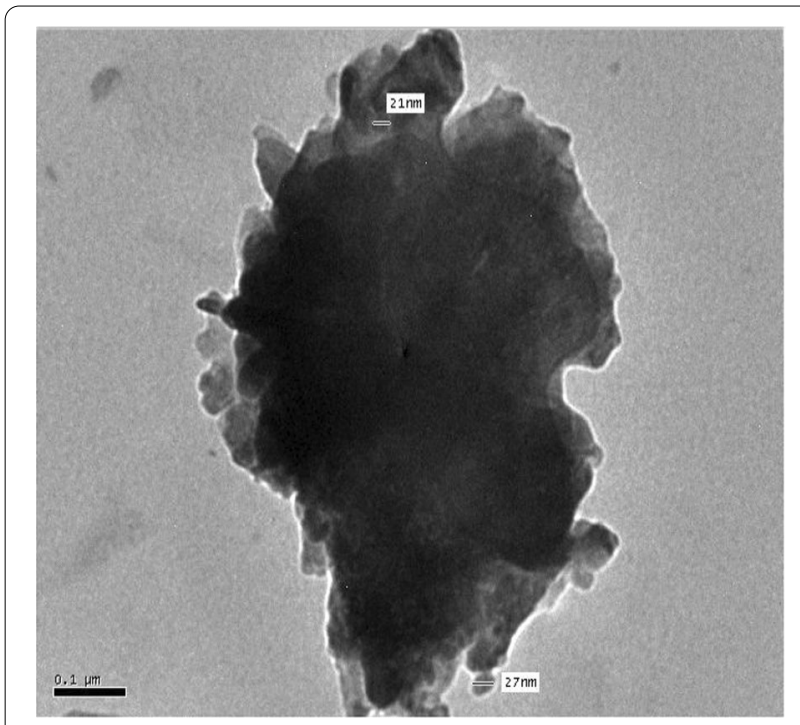

Fig. 2 TEM of pure $C_{3} A$ phase

Two types of aqueous solutions, namely distilled water (DW) and artificial saliva solution, were used as curing liquids. The chemical composition of the artificial saliva solution is given in Table 1 (Shetty et al. 2014).

The preparation of a workable paste of the synthesized composite material was done at a liquid/powder ratio of $0.25 \mathrm{ml} / \mathrm{g}$. The cement pastes were prepared with the aid of cylindrical brass mold $(10 \mathrm{~mm}$ diameter $\mathrm{X}$ $2 \mathrm{~mm}$ height). The paste was filled in the mold into two approximately equal layers. Each layer was compacted and pressed until a homogenous specimen was obtained.
Table 1 Composition of the artificial saliva solution

\begin{tabular}{|c|c|}
\hline Ingredients & $\begin{array}{l}\text { Concentration } \\
\text { (g/L) }\end{array}$ \\
\hline $\mathrm{NaCL}$ & 0.4 \\
\hline $\mathrm{KCl}$ & 0.48 \\
\hline $\mathrm{CaCl}_{2} \cdot 2 \mathrm{H}_{2} \mathrm{O}$ & 0.795 \\
\hline $\mathrm{Na}_{2} \mathrm{SH}_{2} \mathrm{O}$ & 0.005 \\
\hline $\mathrm{NaH}_{2} \mathrm{PO}_{4} 2 \mathrm{H}_{2} \mathrm{O}$ & 0.78 \\
\hline Urea & 1 \\
\hline Phosphoric acid & \\
\hline
\end{tabular}

The samples were cured in the incubator at $37^{\circ} \mathrm{C}$ for $24 \mathrm{~h}$ directly after molding. The samples were de-molded and cured under DW and the prepared artificial saliva solution in the incubator at $37^{\circ} \mathrm{C}$ until testing times at $1,3,7$ and 14 days.

\section{Setting time}

The final setting time of the synthesized bio-cement composite was performed using Vicat apparatus with the best workable past mixed with DW for $30 \mathrm{~s}$ at a water/powder ratio of $0.25 \mathrm{ml} / \mathrm{g}$ as mentioned above. The paste was placed into a disk mold that measured; $10 \mathrm{~mm}$ diameter and $2 \mathrm{~mm}$ in thickness. After $120 \mathrm{~s}$ from the start of mixing, a Gilmore needle (with a flat end diameter of $2 \mathrm{~mm}$ and weighting $100 \mathrm{~g}$ load) was gently lowered to the horizontal surface of the tested material. This procedure was repeated at $30 \mathrm{~s}$ intervals until the indenter failed to make a complete circular mark on the tested material surface. The recorded average setting time of set of five disk samples prepared from the synthesized composite bio-material was taken.

\section{Characterization of the prepared Tri-Calcium aluminate phase \\ $X$-ray diffraction}

The XRD analysis was carried out on some selected hydrated samples with the aid of Philips X-ray diffractometer PW 1730 with $\mathrm{Ni}$-filtered $\mathrm{Cu}-\mathrm{K} \alpha \mathrm{X}$-ray radiation $(\lambda=1.5406 \mathrm{Ao})$ powered at $40 \mathrm{kV}$ and $30 \mathrm{~mA}$. Diffraction data were recorded in the $2 \theta$ range from $5^{\circ}$ to $70^{\circ}$, counting for $10 \mathrm{~s}$ in steps of $\Delta(2 \theta)=0.01^{\circ}$.

\section{ATR/FTIR spectroscopy}

IR spectra were recorded on some selected samples with the aid of JASCO 4600 model FTIR spectrometer.

\section{SEM-EDS analysis}

Investigation of the morphology of some selected cured samples was done by Scanning Electron Microscopy (SEM) together with energy-dispersive X-ray spectra 
(EDX) using an instrument (type Inspect S, T810, D8571, FEI Co., Japan) with an accelerating voltage of $30 \mathrm{kV}$ and a magnification from $10 \times$ to $300,000 \times$.

\section{$\mathrm{pH}$ of the immersion solution}

Disk specimens of cement paste were prepared by mixing with distilled water for $30 \mathrm{~s}$ at a water/powder ratio of $0.25 \mathrm{ml} / \mathrm{g}$. The workable mix was then placed in a mold that (10 mm diameter X $2 \mathrm{~mm}$ height). Then, the prepared discs were directly placed in $20 \mathrm{ml}$ of DW or artificial saliva (Nurit et al. 1993) and kept at $37^{\circ} \mathrm{C}$ in a $100 \%$ humidity water bath for 3,7 and 14 days curing periods. The $\mathrm{pH}$ values of the immersion solution were determined using a solid-state $\mathrm{pH}$ sensor connected to a $\mathrm{pH}$ meter (Medika Scientific Jenway bench top pH meter, England).

\section{Preparation and dental application of the experimental $\mathrm{C}_{3} \mathrm{~A}$-modified glass ionomer}

Modified cements of calcium aluminate glass ionomers were prepared by addition of the experimentally prepared calcium aluminate to the powder component of the conventical glass ionomer cement (CGIC) (Fugi II, GC Gold Label 2, GC Corporation, Tokyo, Japan) prior to mixing the cements according to manufacturer's specifications (Sidhu and Nicholson 2016). Five and ten percent by weight of CGIC powder were replaced by $\mathrm{C}_{3} \mathrm{~A}$ cement and then mixed using ball mill machine (LFJS, Hunan, China) with $200 \mathrm{rpm}$ for $30 \mathrm{~min}$ to produce a homogenous mixed powder (Crowley et al. 2001).

Then, the modified calcium aluminate glass ionomers were tested for their remineralization potential to both sound and caries-affected dentin in vivo in rabbits' teeth. Moreover, the modified calcium aluminate glass ionomers were evaluated in vitro for their shear bond strength to both sound and caries-affected dentin.

\section{In vivo study}

Selection of rabbits Nine healthy adult female NewZealand white rabbits weighing between 3.5 and $4 \mathrm{~kg}$ with age three months were obtained from the Medical Experiment Practice and Research Institute In El Azab El Fayoum). Ethical approval was obtained from the research ethics committee National Research Centre, Egypt (No. 2421022021). Rabbits were kept in individual cages at room temperature under veterinary supervision. They were fed a standard diet as grass, carrot and water (Belduz et al. 2010).

Study design and rabbits grouping A total of 36 teeth were prepared in the nine selected rabbits. Each rabbit contains four teeth (two upper and two lower). A total of thirty six teeth were subdivided into two groups $(n=18$ teeth each) according to the type of dentin substrate, in which the right side teeth of each rabbit was utilized as sound dentin (SD) substrate, while the left side teeth of each rabbit was utilized as artificial caries-affected dentin (CAD) substrate. Then, each dentin substrate was further divided into three subgroups ( $n=6$ teeth each) according to the received cement type: subgroups I: Conventional glass ionomer (CGI) (control), subgroups II: $5 \mathrm{wt} \%$ experimental $\mathrm{Ca}$ aluminate glass ionomer $\left(5 \% \mathrm{C}_{3} \mathrm{~A} \mathrm{GI}\right)$, subgroups III: $10 \mathrm{wt} \%$ experimental $\mathrm{Ca}$ aluminate glass ionomer $\left(10 \% \mathrm{C}_{3} \mathrm{~A} \mathrm{GI}\right)$.

Class $V$ cavity preparation After the sedation of each rabbit with 3 cc propofol I.V. as induction followed by $1 \mathrm{cc}$ propofol as maintain ace, standardized class $\mathrm{V}$ cavities with dimensions $(1.5 \mathrm{~mm} \times 2 \mathrm{~mm})$ (Likitpongpipat et al. 2018) was prepared on the labial surfaces of both upper and lower anterior teeth using round tungsten carbide bur size (\#009) (Komet, Lemgo, Germany) which was changed after every four teeth (Aljandan et al. 2012). Low speed hand piece (NSK, Naskanishi, Japan) was used to prepare the cavities by cutting the tooth structure until the entire head of the round bur disappeared under copious water coolant. An endodontic file stopper was placed at the termination of the bur head to control the depth.

Preparation of artificial caries-affected dentin On each rabbit, the left side prepared cavities on the upper and lower teeth were etched using $37 \%$ phosphoric acid (Meta Biomed, Germany) for $30 \mathrm{~s}$ followed by rinsing for $30 \mathrm{~s}$ to obtain artificial caries-affected dentin (Alrafee et al. 2017).

Application of the cements in the prepared cavities Prepared class V cavities with sound dentin or artificial caries-affected dentin were randomly assigned to the previously mentioned subgroups. Modified Ca aluminate glass ionomer cements (subgroups II, III) or glass ionomer cement (control; subgroups I) were mixed in accordance with manufacturer's instructions with a standard powder/ liquid ratio $(2.7 \mathrm{~g} / 1.0 \mathrm{~g})$ (one level scoop of powder to one drop of liquid), mix up to $30 \mathrm{~s}$ and then placed in the prepared class V cavities on the prepared sound or artificial caries affect dentin surfaces and contoured with a plastic hand instrument ( $3 \mathrm{M}$, ESPE, USA). Restored class V cavities were left in function for 15 days in the rabbits' oral environment.

Extraction of teeth and elemental analysis All rabbits were sacrificed after 15 days following the restorative procedure, and teeth were carefully excised to avoid damage of their surfaces. The cervical portion of the extracted anterior teeth was sectioned mesio-distally to separate each restored tooth cervical portion from 
the remaining tooth portion of crown (to be utilized in the in vitro study). Then, the sectioned restored cervical portion was sectioned cervico-incisally through the center of class $\mathrm{V}$ restoration into two halves using diamond disk (Dental Golden S.A.W., Switzerland) mounted on a low speed hand piece (NSK, Naskanishi, Japan) at (300.000) rpm under copious water coolant. Specimens were analyzed using environmental EnergyDispersive X-ray Analysis (EDX, Model Quanta 250, FEI company, Netherlands) to determine the calcium (Ca) and phosphorous $(\mathrm{P})$ mineral content and the change of the level of these elements percentage due to remineralization. The measurements were taken from three different regions at dentin around the applied cements, and then, the mean of each specimen was calculated.

\section{In vitro study}

Specimens' preparation and grouping Labial enamel of remaining crown segments of the rabbits' teeth that were previously sectioned in the in vivo study was grinded to expose the dentin substrate. A total of 36 dentin disc were prepared and randomly subdivided into two groups ( $n=18 /$ each) according to the type of dentin substrate tested; group I: Sound dentin substrate (SD), while group II: was artificial caries-affected dentin (CAD). Then, each dentin substrate will be further divided into three class ( $n=6 /$ each) according to utilized cements type; subgroup I: Conventional glass ionomer (CGI) (control), subgroup II: $5 \mathrm{wt} \%$ experimental $\mathrm{Ca}$ aluminate glass ionomer $(5 \%$ $\mathrm{C}_{3} \mathrm{~A}$ GI), subgroup III: $10 \mathrm{wt} \%$ experimental Ca aluminate glass ionomer $\left(10 \% \mathrm{C}_{3} \mathrm{~A} \mathrm{GI}\right)$.

Development of artificial caries-affected dentin Half of the dentin specimens were etched using $37 \%$ phosphoric acid for $30 \mathrm{~s}$ followed by rinsing for $30 \mathrm{~s}$ to obtain artificial caries-affected dentin.

Application of the experimental cements A cylindrical transparent plastic tube of inner dimensions $(2 \mathrm{~mm}$ diameter and $3 \mathrm{~mm}$ height) were utilized to act as a mold during cements application. Modified Ca aluminate glass ionomer cements (Group II, III) or glass ionomer cement (control; group I) were mixed and placed in the plastic molds on either the sound or artificial cariesaffected dentin specimens as mentioned before in the in vivo study. After removing the plastic tubes, all the cements cylinders were checked using magnifying glass lens (25s) to detect any defects. Each restored specimen was stored in $15 \mathrm{ml}$ artificial saliva $(\mathrm{pH}=7)$ in an incubator at $37^{\circ} \mathrm{C}$ for 15 days until testing.

\section{Shear bond strength (SBS) test}

Shear bond strength test was carried out for all specimens using a universal testing machine (Lloyd Instruments Ltd;.model LRX-plus;, Fareham, UK). A chisel-shaped shearing blade with a $0.5 \mathrm{~mm}$ width sharp edge was aligned parallel with the flat dentin surface of the bonded specimen. The load cell control system was then adjusted to apply load force of $(5 \mathrm{~N})$ by chisel on dentin-cement interface at a crosshead speed of $0.5 \mathrm{~mm} /$ min until failure occurs. The control system and its associated software recorded the maximum force needed to de-bond each specimen in Newton $(\mathrm{N})$, which was automatically calculated to express the shear bond strength records on output device in Mega pascal (MPa).

\section{Statistical analysis}

The mean and standard deviation values were calculated for each group in each test. Data were explored for normality using Kolmogorov-Smirnov and Shapiro-Wilk tests, data showed parametric (normal) distribution. One-way ANOVA followed by Tukey post hoc test was used to compare between more than two groups in nonrelated samples. Independent sample t-test was used to compare between two groups in non-related samples. Two-way ANOVA was used to test the effect of interaction between different variables. The significance level was set at $p \leq 0.05$. Statistical analysis was performed with IBM ${ }^{\circledR}$ SPSS $^{\circledR}$ Statistics Version 20 for windows.

\section{Results}

\section{Setting time results}

The setting time of the formulated $\mathrm{C}_{3} \mathrm{~A}$ phase composite used in this study was (40 $\mathrm{min} \pm 5.08 \mathrm{~min}$ ).

\section{Results of the characterization of the prepared Tri-Calcium aluminate phase \\ $X$-ray diffraction}

The X-ray diffraction analysis was used in this study to investigate the hydration characteristics of the synthesized aluminate composite pastes cured under artificial saliva solution in comparison with those cured in distilled water. Figure 3 represents the X-ray diffraction patterns of the pure anhydrous tri-calcium aluminate phase $\left(\mathrm{C}_{3} \mathrm{~A}\right)$ in comparison with the prepared composite pastes hydrated for one day and those cured under distilled water and artificial saliva solution for 14 days at $37^{\circ} \mathrm{C}$. It was clear from Fig. 3 that the beaks intensities of the anhydrous $\mathrm{C}_{3} \mathrm{~A}$ phase decrease with the hydration periods for pastes prepared with distilled water after one day curing period and those cured for 14 day under the two 


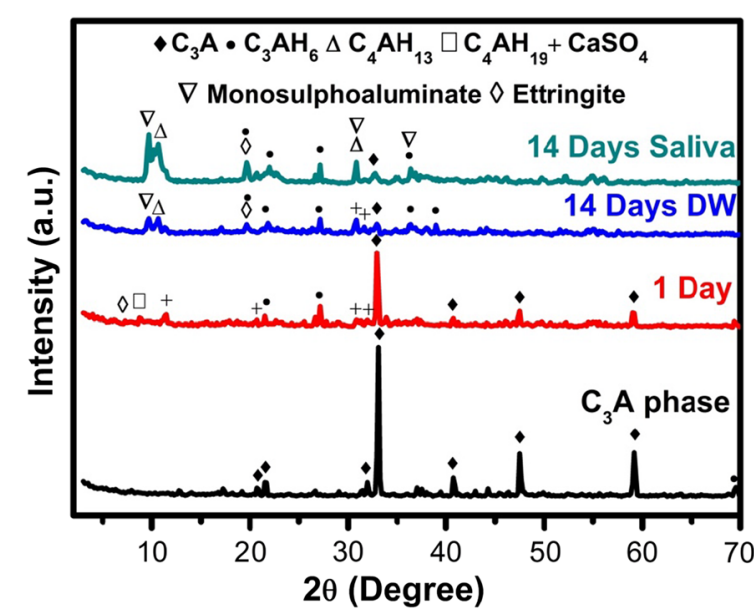

Fig. 3 XRD spectral analysis of the anhydrous $C_{3} A$ phase and cured samples under distilled water and saliva solution for 1 and 14 days

different curing media that was due to the formation of different hydrated phases. The XRD patterns reveal that the hydration reactions proceeded normally, i.e., the main peaks of calcium aluminate hydrates, mono and trisulphoaluminate compounds were found.

The XRD pattern of pastes cured for one day showed the characteristic peaks of trisulphoaluminate compound (ettringite, $\mathrm{C}_{3} \mathrm{~A} .3 \mathrm{CaSO}_{4} \cdot 32 \mathrm{H}_{2} \mathrm{O}$ ) due to the reaction of $\mathrm{C}_{3} \mathrm{~A}$ phase with $\mathrm{CaSO}_{4} \cdot 2 \mathrm{H}_{2} \mathrm{O}$ (gypsum) that was responsible for set regulation of the synthesized phase composite during early hydration period. The characteristic peaks of the residual free gypsum were also detected in this pattern. In this pure system of $\mathrm{C}_{3} \mathrm{~A}$, the added amount of gypsum retards the phase hydration by the formation of the protective impermeable ettringite layer on the $\mathrm{C}_{3} \mathrm{~A}$ surface. The ettringite compound that was formed rapidly after mixing with distilled water reacted with $\mathrm{C}_{3} \mathrm{~A}$ to form the more stable monosulphoaluminate compound $\left(\mathrm{C}_{3} \mathrm{~A} \cdot \mathrm{CaSO}_{4} \cdot 12 \mathrm{H}_{2} \mathrm{O}\right)$ according to Eq. (1 and 2) with an XRD characteristic peak detected in the patterns of the two 14 days samples as shown in Fig. 3 . The XRD patterns of samples cured for 14 days under distilled water and saliva solution showed an increase in peak height of aluminate hydrate compounds $\left(\mathrm{C}_{3} \mathrm{AH}_{6}, \mathrm{C}_{4} \mathrm{AH}_{13}\right.$ and $\mathrm{C}_{4} \mathrm{AH}_{19}$ ) for pastes cured under artificial saliva solution more than those cured under distilled water. The characteristic peak of ettringite (trisulphoaluminate) was found only in the XRD pattern of one day sample, while, that of the monosulphoaluminate compound was found in the pattern of the 14 days samples for both curing media due to chemical reaction of the trisulphate form with $\mathrm{C}_{3} \mathrm{~A}$ phase to form the more stable monosulphate compound according to chemical Eq. 2. As can be seen from Fig. 3, the XRD peaks for monosulphoaluminate

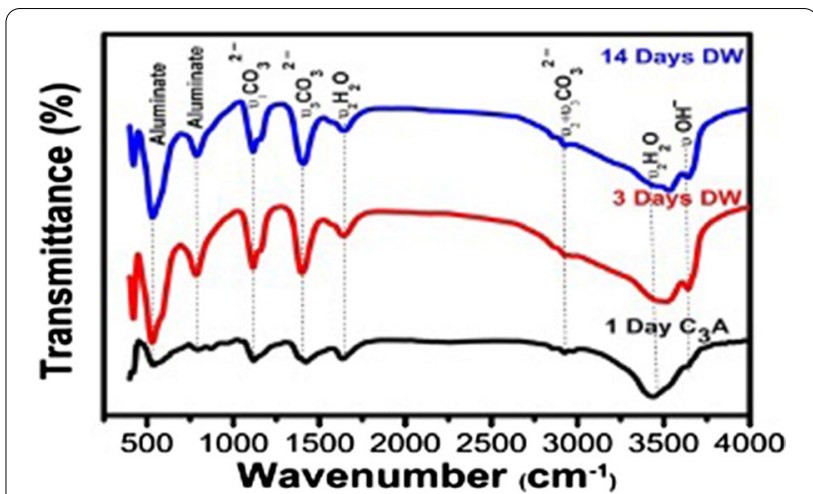

Fig. 4 FTIR spectra of the $C_{3} A$ composite samples cured under distilled water for 1, 3 and 14 days

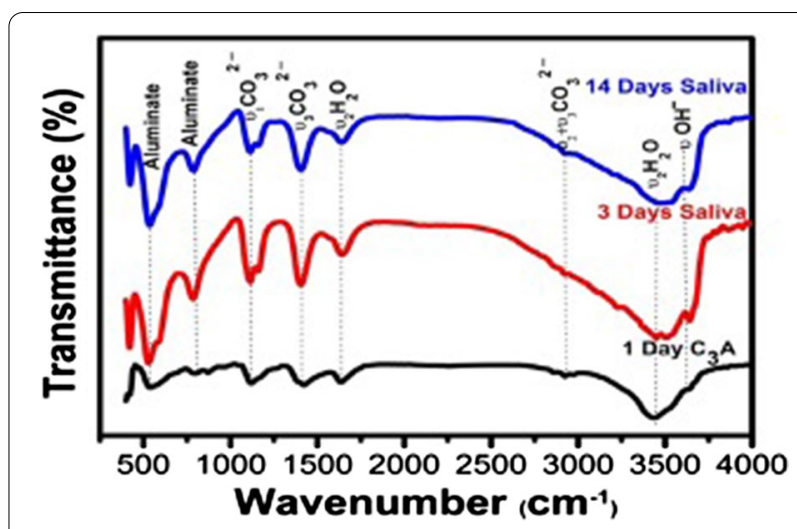

Fig. 5 FTIR spectra of the $C_{3}$ A composite samples cured under artificial saliva solution for 1, 3 and 14 days

compound showed an increasing intensity for the samples cured in saliva solution than those cured in distilled water.

\section{FTIR spectroscopy}

The infrared spectral analysis was carried out on the hydrated paste samples cured for $24 \mathrm{~h}$. and those cured for 14 days under distilled water and artificial saliva solution. The FTIR spectra given in Figs. 4 and 5 indicate the presence of strong aluminate bands at $\sim 25$ and $540 \mathrm{~cm}^{-1}$ correspond to aluminate coupling vibration, weak band at $~ 805$ that overlapped with $\mathrm{U}_{4}$ and $\mathrm{U}_{2}$ for $\mathrm{CO}_{3}{ }^{2-}$ at $~ 715$ and $874 \mathrm{~cm}^{-1}$, respectively, and medium shoulder at $\approx 945$ and $950 \mathrm{~cm}^{-1}$ associated with weak band of $\mathrm{U}_{1} \mathrm{CO}_{3}{ }^{2-}$ at $\sim 1067 \mathrm{~cm}^{-1}$. The very strong wave band at $\sim 1420 \mathrm{~cm}^{-1}$ assigned to $\mathrm{U}_{3} \mathrm{CO}_{3}{ }^{2-}$ and the shoulder for $\mathrm{U}_{4}+\mathrm{U}_{2}, \mathrm{CO}_{3}{ }^{2-}$ at $\sim 2840 \mathrm{~cm}^{-1}$ were detected in the IR spectra. The medium to weak band at $\sim 1645 \mathrm{~cm}^{-1}$ and its associated shoulder at $\sim 1635 \mathrm{~cm}^{-1}$ assigned to the molecular water bending $\mathrm{H}-\mathrm{O}-\mathrm{H}\left(\mathrm{U}_{2}, \mathrm{H}_{2} \mathrm{O}\right)$ are 


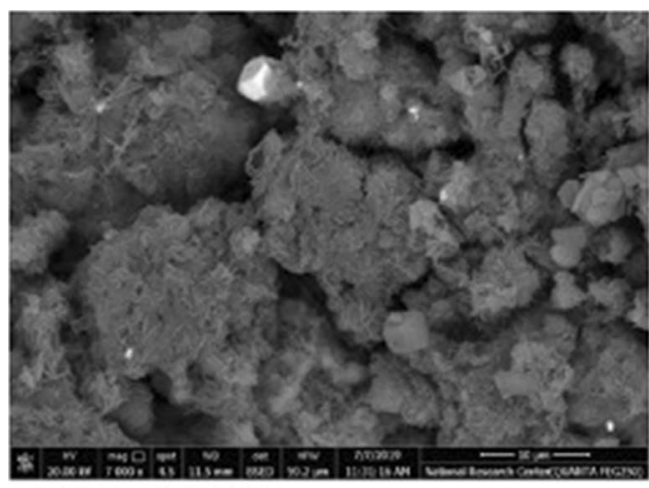

a

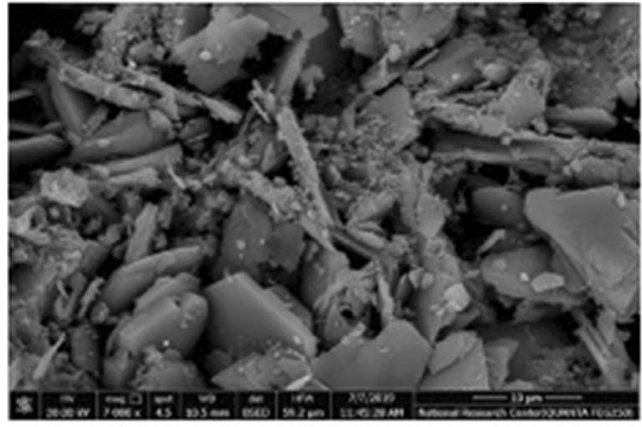

C

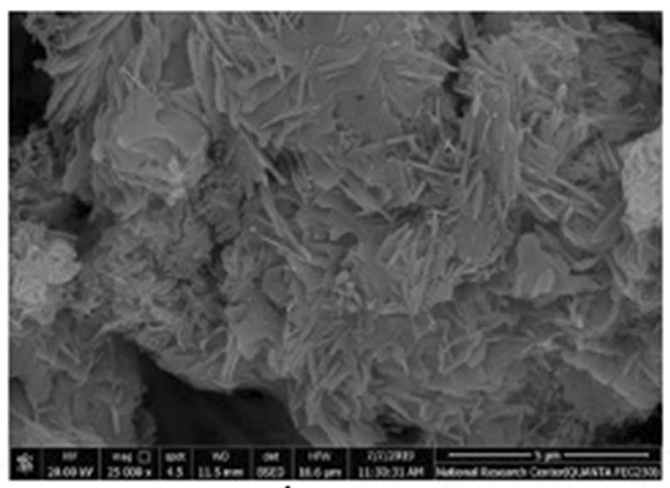

b

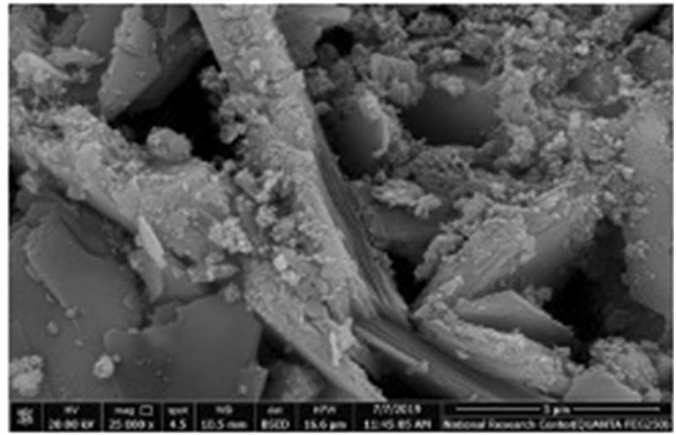

d

Fig. 614 days C3A composite sample cured in distilled water $(\mathbf{a}, \mathbf{b})$ and cured in artificial saliva solution $(\mathbf{c}, \mathbf{d})$

found in Figs. 4 and 5. In addition, the strong broad band at $\sim 3365 \mathrm{~cm}^{-1}$ corresponding to $\mathrm{U}_{2}, \mathrm{H}_{2} \mathrm{O}$ and the band for $\mathrm{OH}^{-}$at $\sim 3620$ and $3670 \mathrm{~cm}^{-1}$ were also seen in the spectra.

\section{SEM-EDS analysis}

The scanning electron microscopy was carried out on some selected hydrated samples to investigate the influence of curing medium on the morphology and crystal forms of the different hydrated aluminate phases. Figure 6 represents the scanning electron micrographs of the hardened paste samples cured for 14 days hydration period under both distilled water (Fig. 6a, b) and saliva solution (Fig. 6c, d).

The micrographs given in Fig. 6 reveal a clear difference in the structural morphology between the samples cured under distilled water and those cured under saliva solution. Generally, accumulation of the hydrated aluminate compounds was found to precipitate over the anhydrous particles and inside the pores which results in a more dense structure. The micrographs of samples cured in distilled water (Fig. 6 a $(7000 \times), b(25,000 \times))$ reflect the difference in morphology compared with the micrograph of samples cured in salvia solution (Fig. $6 \mathrm{c}(7000 \times), \mathrm{d}(25,000 \times))$. Figure 6a shows an agglomerated micro-fine crystals of sulphoaluminate compounds (mono- and tri- forms) that covered the anhydrous particles together with the hexagonal crystals of the hydrated aluminate phases $\left(\mathrm{C}_{4} \mathrm{AH}_{13}\right.$ and $\left.\mathrm{C}_{4} \mathrm{AH}_{19}\right)$. The cubic crystals of the hydrogarnet phase $\left(\mathrm{C}_{3} \mathrm{AH}_{6}\right)$ resulting from the conversion process of the aluminate hydrate compounds were also seen clearly in the micrographs. Figure $6 \mathrm{c}$ and d which represents the micrographs of samples stored in artificial saliva solution showed a dense agglomeration of the hexagonal crystals of aluminate hydrate phases more than those found in Fig. 6a and b. It is also clear that the hydrogarnet cubic crystals were not clearly seen in these micrographs as they may be encapsulated by the aluminate hydrate crystals. Fig. 7A and B represents the EDS graphs of samples cured under the curing media for 14 days. The EDS analysis emphasize the presence of $\mathrm{Ca}, \mathrm{Al}$ and $\mathrm{O}$ elements that were incorporated in the different hydration crystals of C3A phase. It was clear from Fig. (7-B) that there was an increase in the intensities of those elements. EDS analysis also showed the presence of phosphorus peaks in Fig. (7-B). 


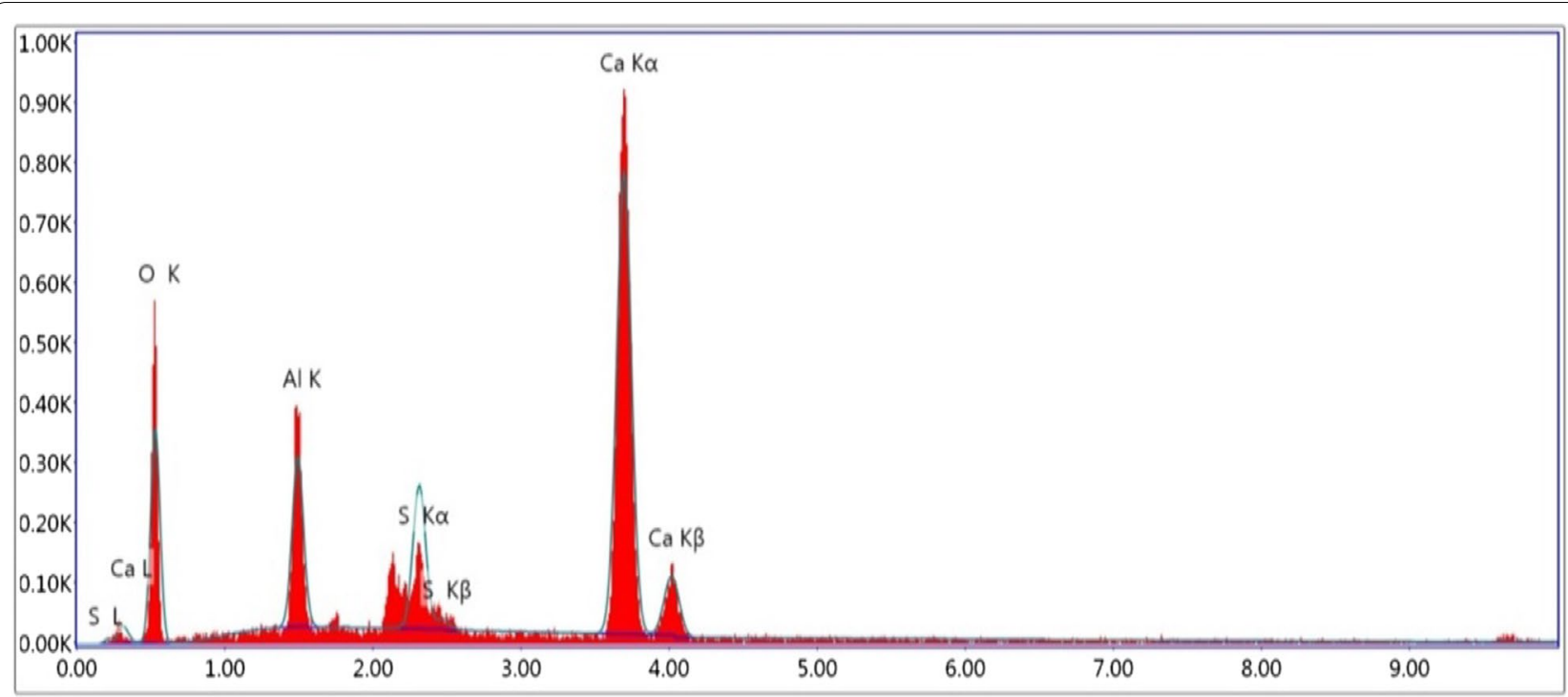

Lsec: 30.00 Cnts 0.000 keV Det: Octane Pro Det Reso

A

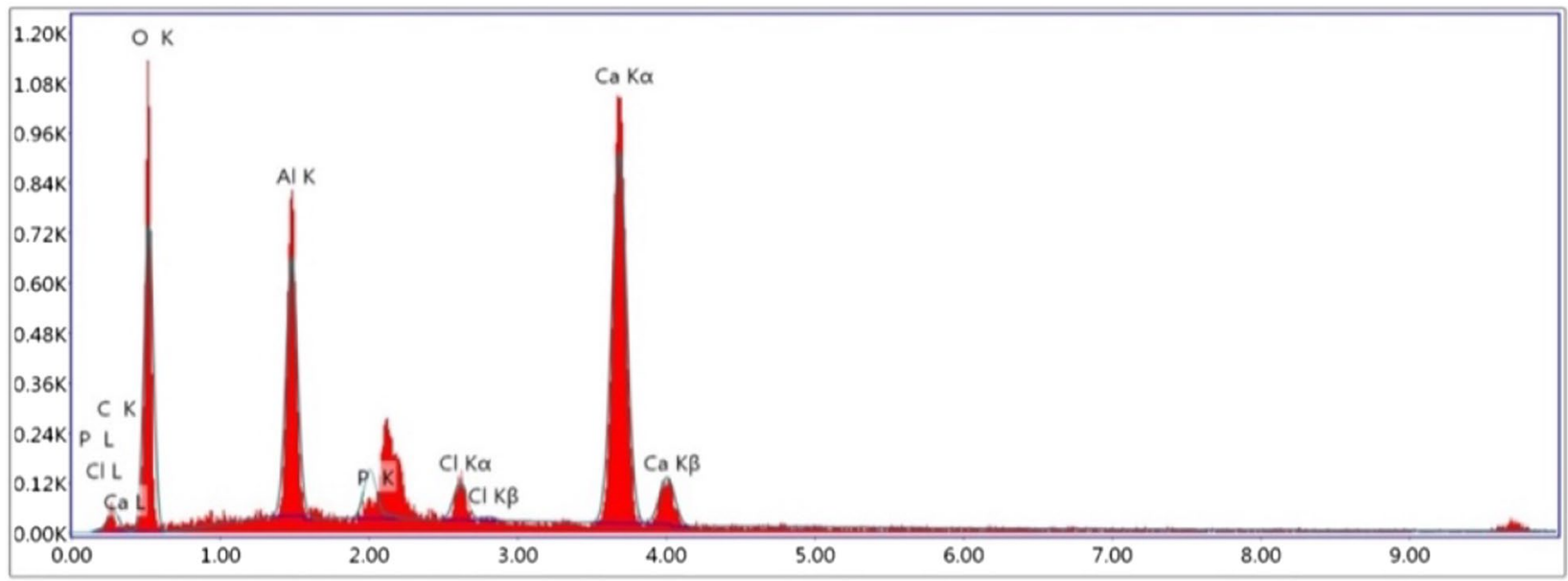

Lsec: 30.00 Cnts 0.000 keV Det: Octane Pro Det Reso

B

Fig. 7 EDS graphs of samples: A- samples cured under distilled water, B- samples cured under artificial saliva solution

\section{$\mathrm{pH}$ of the immersion medium}

Figure 8 represents the $\mathrm{pH}$ values of the immersing media (distilled water and saliva solution) after 3,7 and 14 days curing ages. There was a statistically significant difference between (0 days), (3 days), (7 days) and (14 days) groups for both specimens immersed in distilled water and artificial saliva, where $(p=0.001)$ and $(p=0.002)$, respectively. A statistically significant difference was found between (0 days) and each of (3 days), (7 days) and (14 days) groups where $(p=0.001),(p=0.001)$ and $(p<0.001)$ for distilled water specimens and $(p=0.001),(p=0.002)$ and $(p<0.001)$ for artificial saliva specimens. No statistically significant difference was found between any other groups. While regarding comparing distilled water and artificial saliva specimens results revealed a statistically significant difference between (Distilled water) and (Saliva) groups at 0 and 14 days where $(p<0.001)$ and $(p=0.008)$, respectively. On the other hand, there was no statistically significant difference between (Distilled water) and (Saliva) groups at 3 and 7 days where $(p=0.738)$ and $(p=0.288)$, respectively. 
Table 2 The mean, standard deviation (SD) values of calcium of different groups

\begin{tabular}{|c|c|c|c|c|c|}
\hline \multirow[t]{3}{*}{ Variables } & \multicolumn{5}{|c|}{ Calcium (Ca) } \\
\hline & \multicolumn{2}{|l|}{ SD } & \multicolumn{2}{|l|}{ CAD } & \multirow[t]{2}{*}{$p$ value } \\
\hline & Mean & SD & Mean & SD & \\
\hline CGIC & 25.46 & 2.58 & 11.26 & 0.61 & $0.001^{*}$ \\
\hline $5 \% \mathrm{C}_{3} \mathrm{~A}-\mathrm{GIC}$ & 25.90 & 1.02 & 12.81 & 0.23 & $<0.001^{*}$ \\
\hline $10 \% \mathrm{C}_{3} \mathrm{~A}-\mathrm{Gl}$ & 26.12 & 1.41 & 19.30 & 0.72 & $0.002^{*}$ \\
\hline$p$ value & \multicolumn{2}{|c|}{$0.902 n s$} & \multicolumn{2}{|c|}{$<0.001^{*}$} & \\
\hline
\end{tabular}

ns, non-significant $(p>0.05)$

*Significant $(p<0.05)$

Table 3 The mean, standard deviation (SD) values of Phosphorus of different groups

\begin{tabular}{|c|c|c|c|c|c|}
\hline \multirow[t]{3}{*}{ Variables } & \multicolumn{5}{|c|}{ Phosphorus (P) } \\
\hline & \multicolumn{2}{|l|}{ SD } & \multicolumn{2}{|l|}{ CAD } & \multirow[t]{2}{*}{$p$ value } \\
\hline & Mean & SD & Mean & SD & \\
\hline CGIC & 16.23 & 0.20 & 4.80 & 0.56 & $<0.001^{*}$ \\
\hline $5 \% \mathrm{C}_{3} \mathrm{~A}-\mathrm{GIC}$ & 16.66 & 0.56 & 5.56 & 0.26 & $<0.001^{*}$ \\
\hline $10 \% C_{3} A-G I C$ & 16.83 & 0.47 & 7.97 & 1.95 & $0.002^{*}$ \\
\hline$p$ value & $0.300 \mathrm{~ns}$ & & $0.038^{*}$ & & \\
\hline
\end{tabular}

ns, non-significant $(p>0.05)$

*Significant $(p<0.05)$
Results of the experimental $C_{3} A$-modified Glass lonomer Results of elemental analysis (calcium and phosphorous $w t \%)$

Results of calcium (Ca) wt\%, and phosphorous (P) wt\% (Tables 2, 3) revealed that there was a statistically significant difference between (SD) and (CAD) groups for the three tested materials. While regarding comparing the tested materials on SD, there was no statistically significant difference between them. On the other hand, comparing the tested materials on CAD, a statistically significant difference was found for $\mathrm{Ca} w \mathrm{t} \%$ between (CGIC) and each of (5\% $\left.\mathrm{C}_{3} \mathrm{~A}-\mathrm{GIC}\right)$ and $\left(10 \% \mathrm{C}_{3} \mathrm{~A}-\mathrm{GIC}\right)$ groups where $(p=0.034)$ and $(p<0.001)$, respectively. Also, a statistically significant difference was found between ( $\left.5 \% \mathrm{C}_{3} \mathrm{~A}-\mathrm{GIC}\right)$ and $\left(10 \% \mathrm{C}_{3} \mathrm{~A}-\mathrm{GIC}\right)$ groups where $(p<0.001)$. Where $10 \% \mathrm{C}_{3} \mathrm{~A}-\mathrm{GIC}$ group showed the highest statistically significant mean $\mathrm{Ca}$ wt\% values. For $\mathrm{P}$ wt\%, no statistically significant difference was found between ( $\left.5 \% \mathrm{C}_{3} \mathrm{~A}-\mathrm{GIC}\right)$ and each of (CGIC) and $\left(10 \% \mathrm{C}_{3} \mathrm{~A}-\mathrm{GIC}\right)$ groups where $(p=0.722)$ and $(p=0.102)$. A statistically significant difference was found between (CGIC) and (10\% $\left.\mathrm{C}_{3} \mathrm{~A}-\mathrm{GIC}\right)$ groups where $(p=0.038)$. Figure 9 showed representative figures for the elemental analysis by EDX for different groups.

\section{Results of the shear bond strength}

Table 4 showed results of the shear bond strength for different groups. There was a statistically significant

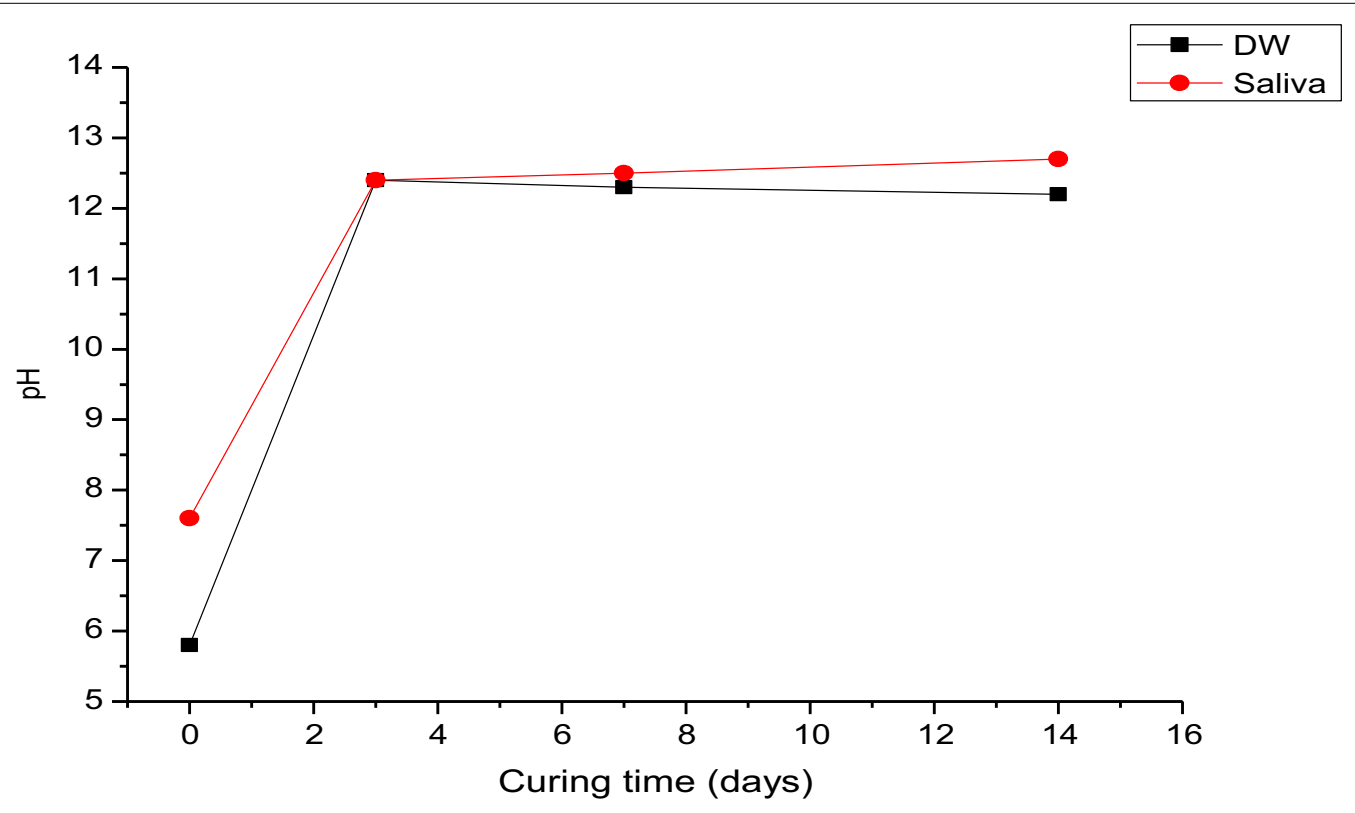

Fig. $8 \mathrm{pH}$ values of the two immersion liquids after zero, 3, 7 and 14 days curing periods 
Table 4 The mean, standard deviation (SD) values of Shear bond strength of different groups

\begin{tabular}{|c|c|c|c|c|c|}
\hline \multirow[t]{3}{*}{ Variables } & \multicolumn{5}{|c|}{ Shear bond strength } \\
\hline & \multicolumn{2}{|l|}{ SD } & \multicolumn{2}{|l|}{ CAD } & \multirow[t]{2}{*}{$p$ value } \\
\hline & Mean & SD & Mean & SD & \\
\hline CGIC & $3.61^{\mathrm{aA}}$ & 0.40 & $2.46^{\mathrm{bA}}$ & 0.63 & $0.008^{*}$ \\
\hline $5 \% \mathrm{C}_{3} \mathrm{~A}-\mathrm{GIC}$ & $3.58^{\mathrm{aA}}$ & 0.29 & $2.54^{\mathrm{bA}}$ & 0.83 & $0.030^{*}$ \\
\hline $10 \% \mathrm{C}_{3} \mathrm{~A}-\mathrm{GIC}$ & $3.53^{\mathrm{aA}}$ & 1.16 & $3.24^{\mathrm{aB}}$ & 0.79 & $0.073 \mathrm{~ns}$ \\
\hline$p$ value & $0.982 \mathrm{~ns}$ & & $0.008^{*}$ & & \\
\hline
\end{tabular}

Different upper case letters in the same column indicating statistically significant difference, while different lower case letters in the same raw indicating statistically significant difference

*: significant $(p<0.05)$, ns: non-significant $(p>0.05)$

difference between (SD) and (CAD) groups for both $(\mathrm{GIC})$ and $\left(5 \% \mathrm{C}_{3} \mathrm{~A}-\mathrm{GIC}\right)$ groups where $(p=0.008)$ and $(p=0.030)$, respectively. While there was no statistically significant difference between (SD) and (CAD) groups with $10 \% \mathrm{C}_{3} \mathrm{~A}-\mathrm{GIC}$ where $(p=0.073)$. Moreover, there was no statistically significant difference between (CGIC), (5\% $\left.\mathrm{C}_{3} \mathrm{~A}-\mathrm{GIC}\right)$ and $\left(10 \% \mathrm{C}_{3} \mathrm{~A}-\mathrm{GIC}\right)$ groups with SD where $(p=0.982)$, while with $\mathrm{CAD}, 10 \% \mathrm{C}_{3} \mathrm{~A}-\mathrm{GIC}$ group showed a statistically significant higher bond strength compared to (CGIC) and ( $\left.5 \% \mathrm{C}_{3} \mathrm{~A}-\mathrm{GIC}\right)$ groups.

Different upper case letters in the same column indicating statistically significant difference, while different lower case letters in the same raw indicating statistically significant difference; * : significant $(p<0.05)$, ns: non-significant $(p>0.05)$.

\section{Discussion}

Progression of dental caries or its reversal relies upon the equilibrium between demineralization and remineralization. Many factors affect this equilibrium such as: the concentration of $\mathrm{Ca}$ and $\mathrm{P}$ in saliva, bio-obtainability of fluoride, $\mathrm{pH}$ and prevention of secondary caries. For the prevention of secondary caries, dentin left in the cavity remineralization is expected to happen due to the usage of highly bioactive adhesive restorative materials (Tamilselvi et al. 2019).

A bioactive material produces a biologic response from the host in the interface and provoke the creation of a band between the material and the tissue. So, the bioactive materials chemically react with body fluids in terms of tissue repair. Moreover, the ability of forming apatite is closely related to the ability of exchanging data with the biological system, this is called interactivity. So, the material capability to stimulate apatite formation on demineralized dentin is greatly correlated with its biointeractivity and bioactivity (Daneshpoor and Pishevar 2020).
The hydration reactions of $\mathrm{C}_{3} \mathrm{~A}$ phase involve the formation of various aluminate hydrate compounds in addition to carbo- and sulphoaluminate hydrates depending upon the chemical composition of the curing medium. Calcium aluminate hydrate compounds of formulas $\mathrm{CAH}_{10}, \mathrm{C}_{2} \mathrm{AH}_{8}$ and $\mathrm{C}_{4} \mathrm{AH}_{19}$ are readily formed at ambient temperature in $\mathrm{CaO} \cdot \mathrm{Al}_{2} \mathrm{O}_{3}$ system (Ramachandran 1969; Taylor 1997; Sarkar et al. 2005).

The setting time of the formulated $\mathrm{C}_{3} \mathrm{~A}$ phase composite used in this study was carried out in accordance with Sect. (2.2) by using the desired amount of distilled water to be $40 \mathrm{~min} \pm 5.08 \mathrm{~min}$. In the current study, $15 \mathrm{wt} \%$ chemically pure Calcium sulphate dihydrate $\left(\mathrm{CaSO}_{4} \cdot 2 \mathrm{H}_{2} \mathrm{O}\right.$; gypsum) was incorporated in the experimentally prepared C3A cement composition in order to regulate setting process and to avoid flash set of the prepared pastes. The $\mathrm{CaSO}_{4} \cdot 2 \mathrm{H}_{2} \mathrm{O}$ (gypsum) reacts with $\mathrm{C}_{3} \mathrm{~A}$ phase to form the ettringite (tri-sulphoaluminate) and the more stable mono-sulphoaluminate compounds that were responsible for set regulation according to the following chemical equations (Taylor 1997):

$$
\begin{aligned}
& \mathrm{C}_{3} \mathrm{~A}+3 \mathrm{CŚ}_{2}+26 \mathrm{H}_{2} \mathrm{O} \rightarrow \mathrm{C}_{3} \mathrm{AS}_{3} \mathrm{H}_{32} \\
& 2 \mathrm{C}_{3} \mathrm{~A}+\mathrm{C}_{6} \mathrm{AS}_{3} \mathrm{H}_{32}+4 \mathrm{H}_{2} \mathrm{O} \rightarrow 3 \mathrm{C}_{4} \mathrm{AS} \mathrm{SH}_{12}
\end{aligned}
$$

The hydration products of $\mathrm{C}_{3} \mathrm{~A}$ in the absence of sulphates and other interfering ions were $\mathrm{C}_{2} \mathrm{AH}_{\mathrm{x}}$ and $\mathrm{C}_{4} \mathrm{AH}_{19}$. It reacts with $\mathrm{H}_{2} \mathrm{O}$ to give $\mathrm{C}_{2} \mathrm{AH}_{8}, \mathrm{C}_{3} \mathrm{AH}_{6}$ and $\mathrm{C}_{4} \mathrm{AH}_{13}\left[\mathrm{C}_{3} \mathrm{~A} \cdot \mathrm{Ca}(\mathrm{OH})_{2} \cdot 12 \mathrm{H}_{2} \mathrm{O}\right]$. The hydrated compound $\mathrm{C}_{2} \mathrm{AH}_{8}$ reacts with free lime $\left[\mathrm{Ca}(\mathrm{OH})_{2}\right]$ if present in the curing medium to form $\mathrm{C}_{4} \mathrm{AH}_{13}$ or $\mathrm{C}_{3} \mathrm{AH}_{6}$ (Taylor 1997; Sarkar et al. 2005). The hydrated compound $\mathrm{C}_{3} \mathrm{AH}_{6}$ crystallizes in the cubic form similar to garnet of chemical formula $\mathrm{Ca}_{3} \mathrm{Al}_{2}\left(\mathrm{SiO}_{4}\right)_{3}$ and of $\left(\mathrm{SiO}_{4}\right)^{4-}$ was replaced by $4(\mathrm{OH})^{-}$as a hexahydrate of composition $\mathrm{Ca}_{3} \mathrm{Al}_{2}(\mathrm{OH})_{2}$ was formed. The hydrated phases $\mathrm{C}_{2} \mathrm{AH}_{8}$ and $\mathrm{C}_{4} \mathrm{AH}_{\mathrm{x}}$ crystallize as a thin hexagonal plates, and the compound $\mathrm{C}_{4} \mathrm{AH}_{19}$ exists in $\alpha 1$ and $\alpha 2$ modifications converted to $\mathrm{C}_{4} \mathrm{AH}_{13}$. These $\alpha$-forms of $\mathrm{C}_{4} \mathrm{AH}_{19}$ may give the formula of $\mathrm{C}_{3} \mathrm{ACaCO}_{3} \cdot 11 \mathrm{H}_{2} \mathrm{O}$ by carbonation reactions (Taylor 1997; Lea 1970).

The reaction of the formulated pure $\mathrm{C}_{3} \mathrm{~A}$ phase composite with water in the presence of small amounts of free unreacted lime $\left[\mathrm{Ca}(\mathrm{OH})_{2}\right]$ present in $\mathrm{C}_{3} \mathrm{~A}$ phase composition at $37^{\circ} \mathrm{C}$ results in the formation of $\mathrm{C}_{4} \mathrm{AH}_{13}$ and $\mathrm{C}_{4} \mathrm{AH}_{19}$ that was converted to the more stable cubic crystals of hydrogarnet $\left(\mathrm{C}_{3} \mathrm{AH}_{6}\right)$ (Matschei et al. 2007). In this research work, this conversion process is more rapid due to the exothermic nature of the hydration reactions of $\mathrm{C}_{3} \mathrm{~A}$ phase in addition to the higher working temperature of the curing media $\left(37^{\circ} \mathrm{C}\right)$. The hydration reaction of $\mathrm{C}_{3} \mathrm{~A}$ phase proceeds through two highly exothermic 
reactions, the first was the formation of tri-sulphoaluminate compound (ettringite) and $\mathrm{C}_{4} \mathrm{AH}_{19}$ during the first 30 min after mixing with distilled water at $37{ }^{\circ} \mathrm{C}$. This elevated curing temperature did not prevent ettringite formation. The second step, at later hydration periods, is typically related to the formation of solid solution of aluminate hydrate phases and mono-sulphate compound according to the following equation, Eq. 3 (Taylor 1997).

$$
\mathrm{C}_{3} \mathrm{~A}+\mathrm{Ca}(\mathrm{OH})_{2}+12 \mathrm{H}_{2} \mathrm{O} \rightarrow \mathrm{C}_{4} \mathrm{AH}_{13}
$$

As can be seen in Fig. 3, the characteristic peaks of the aluminate hydrate compounds $\left(\mathrm{C}_{4} \mathrm{AH}_{13}\right.$ and $\left.\mathrm{C}_{3} \mathrm{AH}_{6}\right)$ were clearly detected in XRD pattern of the 14 days samples, while, for the one day sample only the peaks of the hydrated aluminate phase $\left(\mathrm{C}_{4} \mathrm{AH}_{19}\right)$ was found together with those of hydrogarnet compound $\left(\mathrm{C}_{3} \mathrm{AH}_{6}\right)$ that was formed due to the conversion process mentioned above (Poellmann 1989; Lawrence 1998). The increase in almost all XRD peaks intensities of the aluminate hydrate compounds might be attributed to the presence of different ions in chemical composition of artificial saliva solution [Table 1] that may act as a nucleating centers during the hydration process of $\mathrm{C}_{3} \mathrm{~A}$ phase with an acceleration effect on the hydration reactions by both cations and anions as much of these ions are present in the interlayer spaces and adsorbed on the surface of both anhydrous and hydrated aluminate compounds (Taylor 1997; Lea 1970). The presence of a small amount of $\mathrm{CaCl}_{2} \cdot 2 \mathrm{H}_{2} \mathrm{O}$ (0.04\%) in saliva solution has long been known to accelerate the hydration process of the used material. It may react with $\mathrm{C}_{3} \mathrm{~A}$ phase to form few crystals of chloroaluminate hydrate $\left(\mathrm{C}_{3} \mathrm{~A} \cdot \mathrm{CaCl}_{2} \cdot \mathrm{H}_{2} \mathrm{O}\right)$ that were precipitated in the micropores and could not be detected by XRD as it was encapsulated by other aluminate hydrates (Lea 1970). Artificial saliva solution contains very low concentrations of $\mathrm{NaCl}$ and $\mathrm{KCl}$ salts $(0.04 \%$ and $0.048 \%$, respectively) as given in Table 1 . The ions of these highly ionized salts were sufficiently free in solution and might accelerate the hydration reactions of $\mathrm{C}_{3} \mathrm{~A}$ phase in artificial saliva solution by suggesting the electrolyte effect of such free ions (Glasser et al. 1999; Quennoz and Scrivener 2012).

By following up the IR spectral bands given in Figs. 4 and 5 as a function of hydration period, it was clear that there was an increase in the IR bands of pastes cured for 3 and14 days under both distilled water and artificial saliva solution compared with those of pastes mixed with distilled water for $24 \mathrm{~h}$ that was due to the formation of different hydrated aluminate compounds. The aluminate coupling vibration bands at $\sim 425$ and $540 \mathrm{~cm}^{-1}$ were increased due to the incorporation of the $\mathrm{C}_{3} \mathrm{~A}$ phase in the hydration reactions to form $\mathrm{C}_{3} \mathrm{AH}_{6}, \mathrm{C}_{4} \mathrm{AH}_{13}$ and $\mathrm{C}_{4} \mathrm{AH}_{19}$ hydrated phases together with tri- and mono-sulphoaluminate compounds (ettringite, $\mathrm{C}_{3} \mathrm{~A} \cdot 3 \mathrm{CaSO}_{4} \cdot 32 \mathrm{H}_{2} \mathrm{O}$ and mono-sulphate $\left.\mathrm{C}_{3} \mathrm{~A} \cdot \mathrm{CaSO}_{4} \cdot 12 \mathrm{H}_{2} \mathrm{O}\right)$. This was connected with the increase in band broadening of the molecular water $\mathrm{U}_{2}, \mathrm{H}_{2} \mathrm{O}$ at $\sim 1635 \mathrm{~cm}^{-1}$ and also the IR bands of $\mathrm{OH}-$ at $\sim 3620$ to $3670 \mathrm{~cm}^{-1}$. These findings were in a good agreement with the results of XRD data. The little change of the IR bands between the samples cured for 14 days and those cured for 3 days for both curing media might be attributed to the encapsulation of the formed aluminate hydrate phases on the surface of the anhydrous composite particles especially in case of pastes cured in artificial saliva solution because it accelerates the hydration reactions of tricalcium aluminate phase as was discussed before. The presence of $\mathrm{CO}_{3}{ }^{2-}$ bands was mainly due to the reaction of atmospheric $\mathrm{CO}_{2}$ gas with hydrated aluminate compounds in a process cold carbonation (Lea 1970; Poellmann and Kuzel 1990; Kuzel and Poellmann 1991; Kuzel 1996). Results of XRD were confirmed by the SEM photomicrographs which showed a dens agglomeration of the hexagonal crystals of aluminate hydrate phases in samples cured in artificial saliva.

This study showed that the prepared experimental $\mathrm{C}_{3} \mathrm{~A}$ cement has bioactivity properties. EDS analysis emphasizes the presence of $\mathrm{Ca}, \mathrm{Al}$ and $\mathrm{O}$ elements that were incorporated in the different hydration crystals of $\mathrm{C}_{3} \mathrm{~A}$ phase. It is clear from Fig. 9b that there was an increase in the intensities of those elements due to the enhancement of the hydration reactions rate of pastes cured under artificial saliva solution. EDS analysis also showed the presence of phosphorus peaks in Fig. 7b which was attributed to the formation of small amounts of calcium phosphate crystals on the surface of aluminate hydrate crystals in artificial saliva solution.

Moreover, $\mathrm{pH}$ results showed that the fully hardened material was basic and stay basic through-out its service. This might be attributed to the presence of trace amounts of free lime or unreacted $\mathrm{Ca}(\mathrm{OH})_{2}$ in the composition of the synthesized $\mathrm{C}_{3} \mathrm{~A}$ phase. The $\mathrm{pH}$ values showed a little decrease from 3 to 14 hydration ages for pastes cured in distilled water while in case of artificial saliva solution the $\mathrm{pH}$ values showed a slight increase up to 14 days curing period that might be due to the presence of free ions which act as nucleating centers during the aluminate phase hydration process (Taylor 1997). This property is crucial for the material to be bioactive that is forming apatite on its surface when the material is in contact with phosphate containing solution (artificial saliva).

Conventional glass ionomer cements (CGIC) have many favorable characteristics, as adhesion to enamel and dentin, discharge of fluoride, low thermal expansion coefficients and low shrinkage, low cytotoxicity and excellent compatibility with the pulp (Mahesh et al. 2011; Shikumar et al. 2016). On the other hand, glass ionomers have some shortcomings as: low early mechanical 


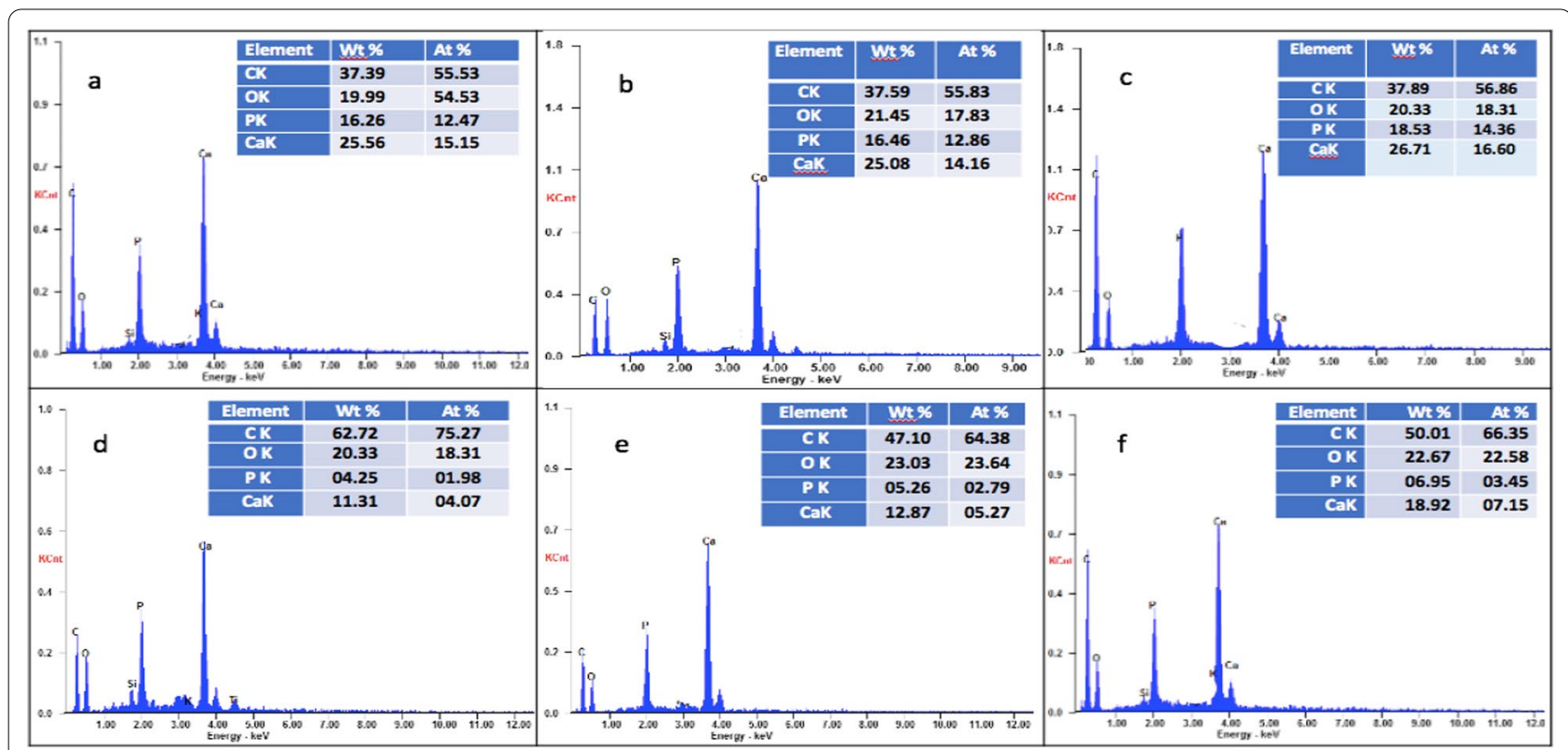

Fig. 9 Representative figures for the elemental analysis by EDX (a). Sound dentin restored with CGIC; (b). Sound dentin restored with 5\% C3A-GIC; (c). Sound dentin restored with 10\% C3A-GIC; (d) CAD restored with CGIC; (e). CAD restored with 5\% C3A-GIC; (f). CAD restored with 10\% C3A-GIC

strength and short working time, moisture sensitivity during the early stages of the setting reaction, inadequate wear-resistance, brittleness and unsatisfactory surface properties (Dhoot et al. 2016). Thus, in order to overcome the low mechanical properties of glass ionomers, many alterations have been created to the conventional GICs. Modifying the conventional GICs by calcium aluminate cement could be beneficial in terms of increasing strength and retention over time; biocompatibility; bioactivity apatite creation; sealing of tooth material interface; durable, constant long-term properties and scarcity of solubility; and greatest development of a stable basic cement $\mathrm{pH}$ (Jefferies 2014).

Energy-dispersive X-ray (EDX) analysis was utilized in the current study to evaluate the remineralization of dentin after the restoration with $\mathrm{C}_{3} \mathrm{~A}-\mathrm{GIC}$. EDX was considered as a non-destructive tool that provides reliable data of the surface composition of the object (Tamilselvi et al. 2019).

Results of the current study using EDX analysis showed a remarkable increase in $\mathrm{Ca}$ and $\mathrm{P}$ wt\% values of the CAD restored with $\mathrm{C}_{3} \mathrm{~A}-\mathrm{GIC}$ (5\%wt, 10\%wt), significantly with the higher concentrations $10 \% \mathrm{wt}$, than the CGIC (control). This might be due to the chemical reaction of tricalcium aluminate which started when reacted with water contained in GI mixing solution. The dissolution of calcium aluminate phase aqueous curing medium had a consequent development of calcium ions $\left(\mathrm{Ca}^{2+}\right)$, aluminum hydroxyl ions $\left(\mathrm{Al}(\mathrm{OH}) 4^{-}\right.$, and hydroxyl ions
$\left(\mathrm{OH}^{-}\right)$. This procedure was then followed instantly by precipitation of new hydrated solid phases mentioned above (tri-sulphoaluminate, mono-sulphoaluminate, $\mathrm{C}_{2} \mathrm{AH}_{8}, \mathrm{C}_{3} \mathrm{AH}_{6}$ and $\mathrm{C}_{4} \mathrm{AH}_{13}$ ) as the solution attains saturation. These precipitates mature and enlarge until they meet, and a linked cluster of hydroxide particles is formed repeatedly. Crystallization of the phases continue and the hydrates enlarge in size from nanometers $(\mathrm{nm})$ to microns $(\mu \mathrm{m})$. Sedimentation and penetration of these crystals into the demineralized tooth surface acts as a template and attracted large amount of $\mathrm{Ca}^{2+}$ and $\mathrm{PO}_{4}{ }^{3-}$ from the in vivo body fluids (saliva, dentinal fluids). These crystals precisely fill up defects and micropores on CAD (demineralized teeth) (Huang et al. 2009). These unique properties as apatite formation and remineralization develop quickly and continue to be active (Chotard et al. 2001; Jefferies 2014).

The shear bond strength (SBS) test was selected in the present study to evaluate the bond strength of the CGIC and the experimental 5\%wt and $10 \%$ wt $\mathrm{C}_{3} \mathrm{~A}-\mathrm{GIC}$ to sound and artificial caries-affected dentin. Shear bond strength testing of restorative materials is one of the widespread techniques to assess its capability to endure stresses of the oral environment. Furthermore, it is considered the most important test for evaluation of restorative materials, because most of intraoral failure occurs through shear forces (Somani et al. 2016; Zhao et al. 2017). Thus, the higher shear bond strength indicates 
advanced bonding and enhanced clinical performance of the material to tooth (Sirisha et al. 2014).

Regarding to the effect of the tooth substrate either; sound or caries-affected dentin on the SBS for the tested cements, results showed that sound dentin had statistically significant higher shear bond strength values than CAD; with both CGIC and 5\%wt $\mathrm{C}_{3} \mathrm{~A}-\mathrm{GIC}$ (Table 4). This might be related to that CAD lost a part of its mineral component from the intertubular dentin during the demineralization procedure (Palma-Dibb et al. 2006). Thus, loss of calcium ions during the demineralization process in caries-affected dentin groups, decrease the chance for bonding between calcium ions and carboxyl groups of polyalkenoic acid. As it is proposed that the chemical bonding mechanism of CGICs is reached through ionic and polar exchanges between calcium ions of hydroxyapatite and carboxyl groups of polyalkenoic acid (Choi et al. 2006).

In addition, chemical and morphological changes that occur in the demineralized CAD as loss of its organic content, increased porosity of intertubular dentin, dissolution of apatite crystals and degradation of collagen fibrils and increasing the permeability might negatively impact the performance of the GIC bonding to it (Alves et al. 2013; Saad et al. 2017).

Results of the SBS showed that $10 \% \mathrm{C}_{3} \mathrm{~A}-\mathrm{GIC}$ showed the highest statistically significant $\mathrm{SBS}$ values when bonded to CAD compared to both $5 \% \mathrm{C}_{3} \mathrm{~A}-\mathrm{GIC}$ and CGIC, Table 4. It seems that the addition of $\mathrm{C}_{3} \mathrm{~A}$ to the CGIC in high concentration (10wt\%) fixed the GIC structure and improved its properties. $\mathrm{C}_{3} \mathrm{~A}$ phase enhanced the hydration chemical reactions with a continuous dissolution/precipitation process which maintained sufficient seal insoluble in tissue fluid and non-resorbable (Sarkar et al. 2005; Shetty et al. 2014).

This might be due to aluminum ions concentration in calcium aluminate rather than conventional type. $\mathrm{Al}^{3+}$ was a main contributor to increase strength as it was supposed to form three-dimensional crosslinks but not $\mathrm{Ca}^{2+}$ or $\mathrm{Sr}^{2+}$, which makes enormous strength difference between glass-ionomer cement and other cements (Burgess et al. 1993; Mitra and Kedrowski 1994). Therefore, the presence of $\mathrm{Al}_{2} \mathrm{O}_{3}$ in the reacted glass particles might precisely also contributed to the mechanical performance of the $\mathrm{C}_{3} \mathrm{~A}-\mathrm{GIC}$ (Mitra and Kedrowski 1994).

This result may refer to a strong reaction between glass ionomer cement matrix and the $\mathrm{C}_{3} \mathrm{~A}$ phase. Which might be also due to the release and precipitation of extra calcium $\left(\mathrm{Ca}^{2+}\right)$ ions from dissoluted Ca-Aluminate in the cement, forming polysalt bridge and cross-linking that all reinforce the cement matrix (Barandehfard et al. 2016). Moreover, the presence of additional hydroxyl $\left(\mathrm{OH}^{-}\right)$and phosphate $\left(\mathrm{PO}^{-3}\right)$ ions from the $\mathrm{C}_{3} \mathrm{~A}$ phase in the intermediate layer between the cement and tooth structure may lead to more hydrogen and ionic bonds between the modified GIC and the tooth structure, with subsequent increase in the GIC bond strength (Moshaverinia et al. 2008).

Moreover, in the chemical reaction the particle size was an important factor, and by decreasing the particle size greater surface area available for interaction (Moshaverinia et al. 2008). Thus, the formed sulphoaluminate fine crystals and hexagonal crystals of aluminate hydrate compounds coating the anhydrous phase particles seen in the XRD, FTIR and the SEM photomicrographs in the current study, could occupied the empty spaces between the glass ionomer powder particles made the GIC mix denser and improved its chemical reactivity. This may lead to enhanced and superior adhesion with subsequent increase in cement bond strength.

\section{Conclusions}

- The hydration process of the synthesized tri-calcium aluminate phase composite proceeded normally under distilled water and artificial saliva solution at $37^{\circ} \mathrm{C}$.

- The free ions (cations and anions) present in artificial saliva solution accelerate the hydration reactions of $\mathrm{C}_{3} \mathrm{~A}$ composite pastes more than those cured under distilled water which results in the formation of more hydrated aluminate compounds at all hydration periods with a delaying effect on the conversion process of the hexagonal crystals of aluminate hydrates to the cubic hydrogarnet crystals that occurred at elevated curing temperatures.

- 10 wt\% Calcium aluminate-modified glass ionomer had a remineralizing effect on artificial cariesaffected dentin under in vivo conditions. Moreover, it had an improved bonding to dentin. Thus, it might be promising restorative/base with advanced remineralization potential and adequate bond strength to both sound dentin and caries-affected dentin.

\footnotetext{
Abbreviations

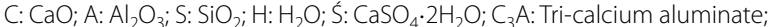
$\mathrm{C}_{3} \mathrm{~A} \cdot 3 \mathrm{CaSO}_{4} \cdot 32 \mathrm{H}_{2} \mathrm{O}$ : Ettringite; $\mathrm{C}_{3} \mathrm{AH}_{6}$ : Hydrogarnet; $\mathrm{C}_{3} \mathrm{~A} \cdot \mathrm{CaSO}_{4} \cdot 12 \mathrm{H}_{2} \mathrm{O}$ : Monosulphoaluminate; $\mathrm{CGIC}$ : Conventional glass ionomer cements; $\mathrm{C}_{3} \mathrm{~A}-\mathrm{GIC}$ Tri-calcium aluminate-modified glass ionomer cement; SBF: Simulated body fluid; CAD: Caries-affected dentin; SD: Sound dentin.
}

\section{Acknowledgements}

Not applicable. 


\section{Authors' contributions}

MMR and SMN performed the study design. MMR prepared the $C_{3} A$ phase. MMR and HKA did all the investigations for the prepared the $C_{3} A$ phase. SMN performed the whole methodology regarding the dental application of the prepared $\mathrm{C}_{3} \mathrm{~A}$ phase to the glass ionomer cement. SMN performed both the in vivo and in vitro studies of the prepared $\mathrm{C}_{3} \mathrm{~A}$ phase-modified glass ionomer cement. MMR and SMN analyzed the data. MMR and SMN were the major contributors in writing the manuscript. All the authors read and approved the final manuscript.

\section{Funding}

This research did not receive any specific grant from backing supports in the public, commercial, or not-for-profit sectors.

\section{Availability of data and materials}

The authors announce that the data supporting the results of this study are existing within the article.

\section{Declarations}

\section{Ethics approval and consent to participate}

Ethical approval was obtained from the research ethics committee National Research Centre, Egypt (No. 2421022021) for the use of animals in the current study.

\section{Consent for publication}

Not applicable.

\section{Competing interests}

The authors declare that they have no competing interests.

\section{Author details}

${ }^{1}$ Refractories, Ceramics and Building Materials Department, National Research Centre (NRC), Dokki 12622, Egypt. ${ }^{2}$ Refractories, Ceramics and Building Materials Department, National Research Centre (NRC), Dokki 12622, Cairo, Egypt. ${ }^{3}$ Restorative and Dental Materials Department, National Research Centre (NRC), 33 El Bohouth st. (former El Tahrir st.), Dokki 12622, Cairo, Egypt.

\section{Received: 11 September 2021 Accepted: 19 October 2021}

Published online: 12 November 2021

\section{References}

Aljandan B, Al Hassan H, Saghah A, Rasheed M, Ali AA (2012) The effectiveness of using different pulp-capping agents on the healing response of the pulp. Indian J Dent Res 23(5):633-637

Alrafee S, Niazy M, El-yassaky M (2017) Remineralization potential of grape seed versus amorphous calciumphosphate nanoparticles on sound and caries affected dentin. ADJ Grils 4:231-237

Alves F, Hesse D, Lenzi T, Guglielmi A, Loguercio AD, Carvalho TS et al (2013) The bonding of glass ionomer cement to caries- affected primary tooth dentin. Pediatr Dent 35:320-324

Barandehfard F, Kianpour RM, Hosseinnia A, Khoshroo K, Tahriri M, Jazayeri HE et al (2016) The addition of synthesized hydroxyapatite and fluorapatite nanoparticles to a glass-ionomer cement for dental restoration and its effects on mechanical properties. Ceram Inter 42:17866-17875

Belduz N, Yilmaz Y, Ozebk E, Kalkan Y, Demirci T (2010) The effect of neodymium- doped yttrium aluminum granet laser irradiation on rabbit dental pulp tissue. Photomed Laser Surg 28(6):747-750

Burgess J, Bargh N, Chan D, Hummert T (1993) A comparative study of three glass ionomer base materials. Am J Dent 6:137-141

Camilleri J, Montesin FE, Brady K, Sweeney R, Curtis RV, Pitt Ford TR (2005) The constitution of mineral trioxide aggregate. Dent Mater 21:297-303

Choi K, Oshida Y, Platt JA, Cochran MA, Matis BA, Yi K (2006) Microtensile bond strength of glass ionomer cements to artificially created carious dentin. Oper Dent 31:590-597
Chotard T, Gimet N, Breart C, Fargeot D, Bonnet JP, Gault C (2001) Application of ultrasonic testing to describe the hydration of calcium aluminate cement at the early age. Cem Concr Res 31(3):405-412

Crowley CM, Pembroke T, Hampshire S (2001) A long term study of setting reaction of glass ionomer cements. Mater Surf Sci Instit 10(2):140-143

Dammaschke T, Gerth HUV, Züchner H, Schäfer E (2005) Chemical and physical surface and bulk material characterization of white ProRoot MTA and two Portland cements. Dent Mater 21:731-738

Daneshpoor N, Pishevar L (2020) Comparative evaluation of bioactive cements on biomimetic remineralization of dentin. J Clin Exp Dent 12:e291-e299

Dhoot R, Bhondwe S, Mahajan V, Lonare S, Rana K (2016) Advances in glass ionomer cement $(\mathrm{GIC})$ : a review. IOSRJ Dent Med Sci 15:124-126

Ezz AA, Shaban A, Abdalla MM, Abbas M (2018) Bonding ability and mechanical strength of recently formulated glass ionomer cements. Al-Azhar J Dent Sci 21(2):147-154

Glasser FP, Kindness A, Stronach SA (1999) Stability and solubility relationships in AFm phases Part I: chloride, sulfate and hydroxi. Cem Concr Res 29:861-866

Hasenwinkel JM, Lautenschlager EP, Wixson RL, Gilbert JL (2013) High strength biological cement composition and using the same. J Biomed Mater Res $47(1): 36-45$

Huang S, Gao S, Yu H (2009) Effect of nano-hydroxyapatite concentration on remineralization of initial enamel lesion in vitro. Biomed Mater 4:341-344

Jefferies S (2014) Bioactive and biomimetic restorative materials: a comprehensive review. Partll J Esthet Restor Dent 26:27-39

Kuzel HJ (1996) Initial hydration reactions and mechanisms of delayed ettringite formation in Portland cement. Cem Concr Res 26:195-203

Kuzel HJ, Poellmann $\mathrm{H}$ (1991) Hydration of C3A in the presence of $\mathrm{Ca}(\mathrm{OH}) 2$ CaSO4.2H2O and $\mathrm{CaCO} 3$. Cem Concr Res 21:885-895

Lawrence LD (1998) The constitution and specification of Portland cements. In: Hewlett PC (ed) Leas's chemistry of cement and concrete. Arnold, London, pp 131-193

Lea FM (1970) The chemistry of cement and concrete, 3rd edn. Edward Arnold, London

Mahesh TR, Suresh P, Sandhyarani J, Sravanthi J (2011) Glass ionomer cements (GIC) in dentistry: a review. IJPAES 1:26-30

Matschei T, Lothenbach B, Glasser FP (2007) The AFm phase in Portland cement. Cem Concr Res 37:118-130

Mitra S, Kedrowski B (1994) Long-term mechanical properties of glass ionomers. Dent Mater 10:78-82

Moshaverinia A, Ansari S, Moshaverinia M, Roohpour N, Darr J, Rehman I (2008) Effects of incorporation of hydroxyapatite and fluoroapatite nanobiocermaics into conventional glass ionomer cements (GIC). Acta Biomater 4:432-440

Nurit J, Margerit J, Terol A, Boudeville P (1993) PH-metric study of the setting reaction of mono phosphate monohydrate/calcium oxide-based cements. J Mater Sci Mater Med 13:1007-1014

Palma-Dibb RG, De Castro CG, Ramos RP, Chimello DT, Chinelatti MA (2006) Bond strength of glass-ionomer to caries-affected dentin. J Adhes Dent 5:57-62

Poellmann H (1989) Solid solution in the system 3CaO.Al2O3.CaSO4.aq3CaO·Al2O3· $\mathrm{Ca}(\mathrm{OH}) 2 \cdot a q$. Neues Jahrb Mineral Abh 161:27-41

Poellmann H, Kuzel HJ (1990) Solid solutions of ettringites; part 1: incorporation of $\mathrm{OH}-$ and $\mathrm{CO}_{3}$ in $3 \mathrm{CaO} \cdot \mathrm{Al}_{2} \mathrm{O}_{3} \cdot 3 \mathrm{CaSO}_{4} \cdot 32 \mathrm{H}_{2} \mathrm{O}$. Cem Concr Res 20:941-947

Quennoz A, Scrivener KL (2012) Hydration of C3A-gypsum systems. Cem Concr Res 42:1032-1041

Rahaman MN, Day D, Bal B, Fu Q, Jung SB, Bonewald LF et al (2011) Bioactive glass in tissue engineering. Acta Bio-Mater 7(6):2355-2373

Ramachandran VS (1969) Application of differential thermal analysis in cement chemistry. Chemical Publishing Company, New York

Saad A, Inoue G, Nikaido T, Ikeda M, Burrow MF, Tagami J (2017) Microtensile bond strength of resin-modified glass ionomer cement to sound and artificial caries-affected root dentin with different conditioning. Oper Dent 42:626-635

Sarkar NK, Caidedo R, Tirwik P, Moiseyeva R, Kawashima I (2005) Physicochemical basis of the biologic properties of mineral trioxide aggregate. J Endod 31:97-100 
Shetty KV, Jhajharia K, Chaurasia VR, Jhamb A, Rohra V, Sharma AM (2014) An in vitro evaluation of the effect of dentin deproteinization on coronal microleakage in endodontically treated teeth. J Int Soc Prev Commun Dent 4:187-192. https://doi.org/10.4103/2231-0762.149036

Shikumar G, Naiza E, Mookambika R, Aanchal A (2016) Newer advances in glass ionomer cement: a review. Ann Ess Dent 8:19-23

Sidhu SK, Nicholson JW (2016) A review of glass-ionomer cements for clinical dentistry. J Funct Biomater 7(3):16-25

Sirisha K, Rambabu T, Shankar Y, Ravikumar P (2014) Validity of bond strength tests: a critical review: Part I. J Conserv Dent 17:305-311

Somani R, Jaidka S, Singh DJ, Sibal GK (2016) Comparative evaluation of shear bond strength of various glass ionomer cements to dentin of primary teeth: An in vitro study. Int J Clin Pediatr Dent 9:192-196

Tamilselvi R, Dakshinamoorthy M, Arumugam K, Sathyapriya B, Lakshmanan P (2019) Effect of CPP ACP and nano hydroxyapatite incorporated GIC on remineralization of dentin. Indian J Public Health Res Dev 10:936-941
Taylor HFW (1997) Cement chemistry, 2nd edn. Thomas Telford Publishing, London

Zhao IS, Mei ML, Zhou ZL, Burrow MF, Lo EC, Chu CH (2017) Shear bond strength and remineralization effect of a casein phosphopeptide-amorphous calcium phosphate-modified glass ionomer cement on artificial "caries-affected" dentine. Inter J Mol Sci 18:1723-1730

\section{Publisher's Note}

Springer Nature remains neutral with regard to jurisdictional claims in published maps and institutional affiliations.

\section{Submit your manuscript to a SpringerOpen ${ }^{\odot}$ journal and benefit from:}

- Convenient online submission

- Rigorous peer review

- Open access: articles freely available online

- High visibility within the field

- Retaining the copyright to your article

Submit your next manuscript at $\boldsymbol{\nabla}$ springeropen.com 